\title{
High-level resistance to class Ila bacteriocins is associated with one general mechanism in Listeria monocytogenes
}

\author{
Anne Gravesen, ${ }^{1} \dagger$ Manilduth Ramnath, ${ }^{1,2}+$ K. Björn Rechinger, ${ }^{1} \ddagger$ \\ Natalie Andersen, ${ }^{1}$ Lothar Jänsch, ${ }^{3}$ Yann Héchard, ${ }^{4}$ John W. Hastings ${ }^{2}$ \\ and Susanne Knøchel ${ }^{1}$
}

Author for correspondence: Anne Gravesen. Tel: +45 3528 3272. Fax: +45 35283231. e-mail: alg@kvl.dk

1 Department of Dairy and Food Science, Centre for Advanced Food Studies, LMC, The Royal Veterinary and Agricultural University, Rolighedsvej 30, DK-1958 Frederiksberg C, Denmark

2 Department of Biochemistry, University of Stellenbosch, Private Bag $\mathrm{X} 1,7602$ Matieland, South Africa

3 German Research Centre for Biotechnology, Department of Cell Biology, Mascheroder Weg 1, Braunschweig D-38124, Germany

4 Laboratoire de Microbiologie Fondamentale et Appliquée, CNRS FRE 2224, IBMIG, UFR Sciences, 40 Avenue du Recteur Pineau, 86022 Poitiers Cedex, France

\begin{abstract}
Class Ila bacteriocins may be used as natural food preservatives, yet resistance development in the target organisms is still poorly understood. In this study, the understanding of class Ila resistance development in Listeria monocytogenes is extended, linking the seemingly diverging results previously reported. Eight resistant mutants having a high resistance level (at least a $1^{3}$-fold increase in MIC), originating from five wild-type listerial strains, were independently isolated following exposure to four different class Ila bacteriocin-producing lactic acid bacteria (including pediocin PA-1 and leucocin A producers). Two of the mutants were isolated from food model systems (a saveloy-type sausage at $10^{\circ} \mathrm{C}$, and salmon juice at $5^{\circ} \mathrm{C}$ ). Northern blot analysis showed that the eight mutants all had increased expression of ElI ${ }^{\mathrm{Bgl}}$ and a phospho- $\beta$-glucosidase homologue, both originating from putative $\beta$-glucosidespecific phosphoenolpyruvate-dependent phosphotransferase systems (PTSs). However, disruption of these genes in a resistant mutant did not confer pediocin sensitivity. Comparative two-dimensional gel analysis of proteins isolated from mutant and wild-type strains showed that one spot was consistently missing in the gels from mutant strains. This spot corresponded to the MptA subunit of the mannose-specific PTS, Ell wild-type strains. The mptACD operon was recently shown to be regulated by the $\sigma^{54}$ transcription factor in conjunction with the activator ManR. Class Ila bacteriocin-resistant mutants having defined mutations in mpt or manR also exhibited the two diverging PTS expression changes. It is suggested here that high-level class lla resistance in L. monocytogenes and at least some other Gram-positive bacteria is developed by one prevalent mechanism, irrespective of wild-type strain, class lla bacteriocin, or the tested environmental conditions. The changes in expression of the $\beta$-glucoside-specific and the mannose-specific PTS are both influenced by this mechanism. The current understanding of the actual cause of class lla resistance is discussed.
\end{abstract}

Keywords: pediocin, PTS, mannose, $\beta$-glucoside, sigma-54

\section{INTRODUCTION}

Class IIa bacteriocins (also called pediocin-like bacteriocins) constitute an abundant, highly homologous family of antimicrobial peptides that are active against the foodborne pathogen Listeria monocytogenes (Cleveland et al., 2001; Ennahar et al., 2000). These compounds are frequently produced by lactic acid bacteria in different types of food. The producer strains or bacteriocins have therefore been suggested as suitable biopreservatives, and some such starter cultures as well as fermentates thereof are now commercially available. However,

† The first two authors contributed equally to this work.

$\ddagger$ Present address: Foss Electric A/S, Slangerupgade 69, DK-3400 Hillerød, Denmark.

Abbreviations: 2D, two-dimensional; PFK, 6-phosphofructokinase; PTS, phosphoenolpyruvate-dependent phosphotransferase system. 
subsequent resistance development in the target organisms is poorly characterized, and remains a major concern.

Cross-resistance between different class IIa bacteriocins has frequently been reported (Dykes \& Hastings, 1998; Ramnath et al., 2000; Rasch \& Knøchel, 1998), indicating an identical or similar resistance mechanism. Previous studies aimed at characterizing mechanisms of class IIa resistance in L. monocytogenes have, however, reported seemingly varying results. Spontaneous resistance development resulted in an increase and a decrease of two different phosphoenolpyruvate-dependent phosphotransferase systems (PTSs), which are responsible for the uptake and concomitant phosphorylation of a number of sugars in both Gram-negative and Gram-positive bacteria (for a review, see Postma et al., 1993). A leucocin A-resistant mutant of L. monocytogenes $\mathrm{B} 73$ no longer synthesized the IIAB subunit of a mannose-specific PTS (Ramnath et al., 2000), and 12 independent mutants of L. monocytogenes 412 overexpressed two $\beta$-glucoside-specific PTS genes (Gravesen et al., 2000). A mutant with resistance to divercin V41 had several changes in protein synthesis, which was suggested to be due to a mutation in a sigma transcription factor (Duffes et al., 2000). This suggestion was partly based on the fact that transposon mutagenesis of rpoN, encoding the $\sigma^{54}$ transcription factor, conferred resistance to the IIa bacteriocin mesentericin Y105 (Robichon et al., 1997). Recently, the mannose-specific PTS, EII ${ }_{t}^{\text {Man }}$, was shown by the construction of defined mutants to be directly involved in sensitivity to mesentericin Y105, and a specific domain of the MptD subunit was suggested to be involved in target recognition by the bacteriocin (Dalet et al., 2001).

One explanation for the apparently diverging results may be that the specific strain in each study developed resistance by different mechanisms. Alternatively, the diverse observations could be 'windows' to the same, complex mechanism, revealed by the different experimental approaches. If different mechanisms do exist, it is conceivable that resistance developed in foods would differ from that developed under standard laboratory conditions.

The aim of the present study is to resolve the differences observed in previous work regarding class IIa resistance in L. monocytogenes, and to further the understanding of the underlying mechanisms, focusing on food relevance. We have compared IIa resistance developed in a panel of listerial wild-type strains following exposure to different IIa bacteriocins in a range of systems, including food. Our results indicate that one general mechanism is responsible for spontaneous class IIa resistance development in L. monocytogenes, and possible models incorporating the different observations are discussed.

\section{METHODS}

Bacterial strains and growth conditions. The L. monocytogenes wild-type strains and mutants are described in Table 1. Wild-type strains and spontaneous mutants were cultured in brain-heart infusion broth (BHI; Difco) at 30 or $37^{\circ} \mathrm{C}$ without agitation, and the bacteriocin resistance or sensitivity phenotypes of harvested cultures were verified by plating on tryptone soya agar (TSA; Oxoid) plates supplemented with $30 \%$ pediocin PA-1 fermentate (see below). The deletion and insertional mutants were cultured in $\mathrm{BHI}$ at $37^{\circ} \mathrm{C}$, and chromosomal integration in harvested cultures was verified by parallel enumeration at 37 and $42{ }^{\circ} \mathrm{C}$ on TSA containing $5 \mu \mathrm{g}$ erythromycin $\mathrm{ml}^{-1}$ or by PCR using primers complementary to the vector and to chromosomal DNA adjacent to the insert.

Class Ila bacteriocins. The class IIa bacteriocins used in this study were all prepared as fermentates of the producer organisms: Pediococcus acidilactici PA-2 producing pediocin PA-1 (Chr. Hansen A/S, Hørsholm, Denmark), Leuconostoc gelidum UAL 187-22 producing leucocin A (Papathanasopoulos et al., 1997), Leuconostoc carnosum 4010 (Danish Meat Research Institute, Roskilde, Denmark) and Carnobacterium piscicola A9b (Nilsson et al., 1999). Ammonium sulphate-precipitated fermentate of C. piscicola A9b was kindly supplied by Lilian Nilsson (Danish Institute for Fisheries Research, Lyngby, Denmark) and was added at $1 \%$ to TSA agar supplemented with $0 \cdot 1 \%$ Tween 80 . For the three other producer strains, stationary-phase cultures in de Man, Rogosa, Sharp broth (Oxoid) were catalase-treated and the $\mathrm{pH}$ adjusted to 6.5 with $5 \mathrm{M} \mathrm{NaOH}$. The fermentate was subsequently harvested and sterile-filtered, and stored at $-80^{\circ} \mathrm{C}$ until use. Synthetic leucocin A (Ramnath et al., 2000) was kindly supplied by S. Aimoto and K. Tamura (Osaka, Japan).

MIC of leucocin A. The MICs were determined by a spot-onlawn assay, essentially as described previously (Ramnath et al., 2000). Five-microlitre spots of a twofold serial dilution of $4 \mathrm{mg}$ synthetic leucocin $\mathrm{A} \mathrm{ml}^{-1}$ in $0 \cdot 1 \%$ trifluoroacetic acid was spotted onto BHI agar lawns $(0.7 \%$ agar, $0.1 \%$ Tween 80) containing approx. $10^{7}$ c.f.u. listerial cells $\mathrm{ml}^{-1}$. The MIC was determined as the minimal concentration giving a visible zone of inhibition after $20 \mathrm{~h}$ at $37^{\circ} \mathrm{C}$, as the median of three to four independent experiments.

Insertional inactivation of the putative $\boldsymbol{\beta}$-glucoside-specific PTS genes. The putative $\beta$-glucoside-specific PTS enzyme II $\left(\mathrm{EII}^{\mathrm{Bg} 1}\right.$, annotated as $\left.l m o 00027\right)$ and the phospho- $\beta$-glucosidase (Imo00319), which were overexpressed following pediocin resistance development in L. monocytogenes 412 (Gravesen et al., 2000), were inactivated in L. monocytogenes 412 and 412P using the $9 \mathrm{~kb}$ temperature-sensitive integration vector pAULA (Chakraborty et al., 1992). For $\mathrm{EII}^{\mathrm{Bg} 1}$, a 1306 bp PCR fragment was made from chromosomal DNA of L. monocytogenes 412P using primers P1 (5'-CATCTGCTAAAGTTACGATTTCGCC-3') and X2 (5'-AAYCAYGTNCCNGAYGT3', where the mixed bases $\mathrm{N}$ and $\mathrm{Y}$ correspond to ACGT and $\mathrm{CT}$, respectively). P1 was designed from the previously found C-terminal gene fragment (Gravesen et al., 2000), and the degenerate primer X2 was designed from an N-terminal conserved region in $\beta$-glucoside-specific EII permeases. An internal $674 \mathrm{bp}$ EcoRI restriction fragment of the PCR product was cloned in pAUL-A, resulting in pAG540. This plasmid was transformed to L. monocytogenes 412 and $412 \mathrm{P}$ by electroporation (Park \& Stewart, 1990) and integrated into the chromosome by propagation at $42{ }^{\circ} \mathrm{C}$ in the presence of $5 \mu \mathrm{g}$ erythromycin $\mathrm{ml}^{-1}$ (Chakraborty et al., 1992), resulting in strains L. monocytogenes AG122 and AG119, respectively. For inactivation of the phospho- $\beta$-glucosidase, a 991 bp PCR product made with primers P3 (5'-GGACTTTCCGTTCAAGATG-3') and P4 (5'-GTGGTTTTTGGTATCTATCC-3') was cloned in pAUL-A, giving plasmid pAG538. The two primers were designed from the two previously found frag- 
Table 1. Listeria monocytogenes strains

Spontaneous mutants isolated in this study were selected on tryptone soya agar $\left(\mathrm{pH} 6.5,30^{\circ} \mathrm{C}\right)$ containing fermentates from $P$. acidilactici PA-2 (ped PA-1), Leuconostoc gelidum UAL 187-22 (leu A), Leuconostoc carnosum 4010 (leu 4010) and C. piscicola A9b (carn A9b). Mutants in food systems were isolated as survivors following challenge with Leuconostoc carnosum 4010 in a saveloytype meat model at $10^{\circ} \mathrm{C}$ (leu 4010), or with C. piscicola A9b in salmon juice at $5{ }^{\circ} \mathrm{C}$ (carn A9b). Imo00027 encodes a putative $\beta$ glucoside-specific PTS enzyme II, EII ${ }^{\mathrm{Bg} 1}$; lmo00319 encodes a putative phospho- $\beta$-glucosidase.

\begin{tabular}{|c|c|c|c|}
\hline L. monocytogenes & $\begin{array}{l}\text { Leucocin A MIC } \\
\qquad\left(\mu \mathrm{g} \mathrm{ml}^{-1}\right)\end{array}$ & Description & Reference or source* \\
\hline \multicolumn{4}{|l|}{ Wild-type isolates } \\
\hline 412 & $0 \cdot 98$ & Wild-type from raw, salted pork & Gravesen et al. (2000) \\
\hline B73 & $0 \cdot 98$ & Wild-type from meat & Dykes \& Hastings (1998) \\
\hline EGDe & $1 \cdot 95$ & Clinical & Glaser et al. (2001) \\
\hline 386 & $0 \cdot 98$ & Wild-type from heat-treated pork & Anette Granly Larsen, DMRI \\
\hline O57 & $1 \cdot 95$ & Wild-type from lightly pickled salmon & Ben Embarek \& Huss (1993) \\
\hline \multicolumn{4}{|l|}{$\begin{array}{l}\text { Spontaneous } \\
\text { mutants }\end{array}$} \\
\hline $412 \mathrm{P}$ & $>4 \times 10^{3}$ & Mutant of 412 isolated on pediocin PA-1 & Gravesen et al. (2000) \\
\hline 412L-A1 & $>4 \times 10^{3}$ & Mutant of 412 isolated on leu A & This work \\
\hline 412L2 & $>4 \times 10^{3}$ & Mutant of 412 isolated on leu 4010 & This work \\
\hline $412 \mathrm{C} 2$ & $>4 \times 10^{3}$ & Mutant of 412 isolated on carn A9b & This work \\
\hline B73-MR1 & $>4 \times 10^{3}$ & Mutant of B73 resistant to leucocin A & Ramnath et al. (2000) \\
\hline EGDeP4 & $>4 \times 10^{3}$ & Mutant of EGDe isolated on ped PA-1 & This work \\
\hline DMRICC 4053 & $>4 \times 10^{3}$ & $\begin{array}{l}\text { Mutant of } 386 \text { isolated from a meat model containing } \\
\text { leu } 4010\end{array}$ & Anette Granly Koch, DMRI \\
\hline $3.33 \mathrm{~A}$ & $>4 \times 10^{3}$ & $\begin{array}{l}\text { Mutant of } 057 \text { isolated from salmon juice containing } \\
\text { carn A9b }\end{array}$ & Lilian Nilsson, DIFRES \\
\hline \multicolumn{4}{|l|}{ Defined mutants } \\
\hline AG115 & $0 \cdot 98$ & Insertional inactivation of $\operatorname{lmo} 00319$ in strain 412 & This work \\
\hline AG117 & $>4 \times 10^{3}$ & Insertional inactivation of $\operatorname{lmo} 00319$ in strain $412 \mathrm{P}$ & This work \\
\hline AG119 & $>4 \times 10^{3}$ & Insertional inactivation of $\operatorname{lmo} 00027$ in strain $412 \mathrm{P}$ & This work \\
\hline AG122 & $0 \cdot 98$ & Insertional inactivation of $\operatorname{lmo} 00027$ in strain 412 & This work \\
\hline EGK51 & $>4 \times 10^{3}$ & Insertional inactivation of $\operatorname{manR}$ in strain EGDe & Dalet et al. (2001) \\
\hline EGK54 & $>4 \times 10^{3}$ & Insertional inactivation of $m p t A$ in strain EGDe & Dalet et al. (2001) \\
\hline EGY2 & $>4 \times 10^{3}$ & $84 \mathrm{bp}$ in-frame deletion in $m p t D$ in strain EGDe & Dalet et al. (2001) \\
\hline
\end{tabular}

*DMRI, Danish Meat Research Institute, Roskilde, Denmark; DIFRES, Danish Institute for Fisheries Research, Lyngby, Denmark.

ments of the gene (Gravesen et al., 2000). Chromosomal integration of pAG538 in L. monocytogenes 412 and 412P resulted in strains L. monocytogenes AG115 and AG117, respectively. Correct integration was verified by PCR using standard primers complementary to the vector sequence combined with a primer recognizing a chromosomal region adjacent to the segment employed for insertion. For the EII gene, primer P1 was used. For the phospho- $\beta$-glucosidase, primer P4X (5'-ATAGCGCCAAGTCCGTTCTC-3'), situated $20 \mathrm{bp}$ downstream of P4, was used. The class IIa bacteriocin sensitivity of the insertional mutants was tested by plating on TSA supplemented with $30 \%$ pediocin PA-1 fermentate, and by determining the MIC for leucocin A.

Northern hybridization. Expression analysis of the putative $\beta$ glucoside-specific PTS genes was modified after Gravesen et al. (2000). Cells were harvested from late-exponential cultures $\left(\mathrm{OD}_{600}\right.$ approx. $0 \cdot 4-0 \cdot 6$, depending on the strain) grown in $\mathrm{BHI}, \mathrm{pH} 7 \cdot 2$, at $30^{\circ} \mathrm{C}$ without selection, and lysed with a FastPrep FP 120 instrument (Bio 101) at a power setting of $6.0 \mathrm{~m} \mathrm{~s}^{-1}$ for $45 \mathrm{~s}$. For analysis of insertional and deletion mutants, these strains and the corresponding wild-types were cultured at $37^{\circ} \mathrm{C}$. RNA was purified with the RNeasy Mini kit
(Qiagen). The probe for $\mathrm{EII}^{\mathrm{Bg} 1}$ was the fragment A RFDD (restriction fragment differential display) PCR product (Gravesen et al., 2000) encompassing 292 bp of the permease. For the putative phospho- $\beta$-glucosidase, the 991 bp P3-P4 PCR product was used. The probes were labelled with $[\alpha-$ $\left.{ }^{33} \mathrm{P}\right] \mathrm{dATP}$, and hybridization was visualized with a STORM 840 PhosphorImager (Molecular Dynamics).

Protein extraction for two-dimensional (2D) gel electrophoresis. L. monocytogenes strains were grown until lateexponential phase $\left(\mathrm{OD}_{600} 0.45-0 \cdot 5\right)$ in $\mathrm{BHI}, \mathrm{pH} 7 \cdot 2,37^{\circ} \mathrm{C}$. Chloramphenicol (Sigma) was added at a final concentration of $20 \mu \mathrm{g} \mathrm{ml}^{-1}$ to halt protein synthesis. Bacterial cells were harvested, washed, resuspended in buffer containing Complete Mini tablets (protease inhibitors; Roche), and stored at $-80{ }^{\circ} \mathrm{C}$. Once thawed, cell suspensions were disrupted using the FastPrep FP 120 instrument at a power setting of 6.5 for $45 \mathrm{~s}$. This cycle was repeated five times, with chilling of the tubes on ice between cycles. The cell lysate was treated with DNase I and RNase I, and, subsequently, 9.5 M urea, $100 \mathrm{mM}$ DTT (Sigma), $4 \%$ (w/v) CHAPS and 2\% (v/v) Pharmalyte (pH 3-10) were added. The supernatant was clarified by centrifugation and stored at $-80{ }^{\circ} \mathrm{C}$. All reagents for the 
protein isolation and 2D gel electrophoresis were from Amersham Pharmacia Biotech, unless stated otherwise.

First-dimension electrophoresis. Isoelectric focusing was carried out on immobilized $\mathrm{pH}$ gradients, $\mathrm{pH} 4-7(11 \mathrm{~cm}$ Immobiline Drystrips), on a Multiphor II apparatus according to the manufacturers' instructions. The following voltage gradient was applied: from 0 to $300 \mathrm{~V}$ in $0.01 \mathrm{~h} ; 300 \mathrm{~V}$ for $6.5 \mathrm{~h}$; from 300 to $3500 \mathrm{~V}$ in $5 \mathrm{~h}$; and $3500 \mathrm{~V}$ for $8 \mathrm{~h}$. Protein samples were cup-loaded at the anodic end. For zoom gels, $18 \mathrm{~cm}$ Immobiline Drystrips, $\mathrm{pH} 5-6$, were used, protein samples were loaded via rehydration, and isoelectric focusing was run according to the manufacturer's instructions.

Second-dimension electrophoresis. Prior to the SDS-PAGE run, isoelectric focusing strips were equilibrated in an SDS equilibration buffer as recommended by the manufacturer, with the following modifications: (1) the concentration of SDS in the SDS equilibration buffer was increased to $4 \%(\mathrm{w} / \mathrm{v})$; and (2) the concentration of iodoacetamide (Sigma) for the second equilibration step was increased to $4 \%$ (w/v). Each equilibration step was carried out for $30 \mathrm{~min}$. The seconddimension run was carried out on pre-cast ExcelGel XL SDS 12-14 gels according to the manufacturer's instructions. Gels were stained with either Coomassie brilliant blue or silver, and dried as described previously (Rechinger et al., 2000). For the extended run of the zoom gel, electrophoresis was stopped after the normal run, the buffer strips were replaced, and the run was resumed for another $2 \mathrm{~h}$.

2D gel analysis. For each protein sample, at least one Coomassie-stained and one silver-stained gel were examined. Images of Coomassie-stained gels were scanned at a resolution of 200 d.p.i. Quantification and spot matching between gels were done using Z3 Desk Top version 2.0 (Compugen). Differences of at least fourfold up-regulation or $0 \cdot 3$-fold downregulation were noted by comparison of the 200 most intense spots on the gels of resistant mutants when compared with the corresponding wild-type strain gels. Differences that were found by $\mathrm{Z} 3$ analyses were verified by visual examination.

Identification of protein samples by MS. Protein samples from L. monocytogenes EGDe were excised from Coomassiestained gels, and in-gel tryptic digestions were carried out overnight. The peptides generated were subjected to electrospray analysis and subsequent peptide sequencing using a quadrupole time-of-flight MS instrument (Q-TOF II; Micromass) equipped with a nanospray ion source. Doubly and triply charged peptides were chosen for collision-induced MS/MS fragmentation experiments, and the corresponding parent ions were selectively transmitted from the quadrupole mass analyser into the collision cell. The resulting daughter ions were separated by an orthogonal time-of-flight mass analyser. Peptide micro-sequencing and protein identification was carried out with the Peptide-Sequencing program within the Biolynx software (version 3.4; Micromass) and with the Sonar program (Proteometrics). The trypsin fragment sequences obtained were compared with the proteins predicted from the L. monocytogenes EGDe genome sequence (http:// genolist.pasteur.fr/ListiList/). Predicted molecular mass and pI values were calculated at the Expasy site (http:// www.expasy.ch/tools).

\section{RESULTS}

\section{Resistance levels of the isolated mutants}

The resistance levels of the spontaneous IIa mutants were assessed by comparing the mutant and wild-type MICs for leucocin A (Table 1). All eight mutants were unaffected by the highest concentration (4 mg synthetic leucocin $\mathrm{A} \mathrm{ml}^{-1}$ ) used. This corresponds to an at least $2 \times 10^{3}$-fold increase in resistance compared to the respective wild-type strain. L. monocytogenes EGK51, EGK54 and EGY2, which are defined mutants of strain EGDe, also had a MIC of over $4 \mathrm{mg}$ leucocin $\mathrm{A} \mathrm{ml}^{-1}$, in concordance with the previous observation of a high level of resistance to mesentericin Y105 (Dalet et al., 2001). All mutants were also resistant to the fermentates of the four producer strains, showing cross-resistance between the bacteriocins used.

\section{Analysis of expression of the putative $\beta$-glucoside- specific PTS genes}

The result of the Northern analysis of the spontaneous mutants employing the $\mathrm{EII}^{\mathrm{Bgl}}$ probe is shown in Fig. 1(a). All eight mutants had a constitutive increase in expression compared to the wild-type strains, which did not have detectable transcription of this gene. The level of the increase varied for the different mutants. There was, however, no correlation between level of increase in expression and level of resistance: the two mutants with low expression, EGDeP4 and DMRICC 4053, had as high resistance to leucocin A as the other mutants. Northern analysis of further 29 high-level-resistant spontaneous mutants of 11 other wild-type strains and of the defined mutants L. monocytogenes EGK51, EGK54 and EGY2 showed that these all had increased expression of the EII ${ }^{\mathrm{Bgl}}$ (results not shown).

The analysis with the probe for the putative phospho- $\beta$ glucosidase showed that this gene also had increased expression in the eight spontaneous mutants (Fig. 1b). Again, varying levels of increase were observed, but there was no correlation to level of resistance or to level of increase of $\mathrm{EII}^{\mathrm{Bg} \mathrm{l}}$ expression. Further studies of another 21 spontaneous mutants showed that 20 of these had increased expression of the phospho- $\beta$-glucosidase (results not shown).

\section{Effect of inactivation of the putative $\beta$-glucoside- specific PTS genes on Ila sensitivity}

EII ${ }^{\mathrm{Bg} 1}$ and the putative phospho- $\beta$-glucosidase were inactivated in L. monocytogenes 412 and $412 \mathrm{P}$ by plasmid integration using a $674 \mathrm{bp}$ and a $991 \mathrm{bp}$ internal gene fragment, respectively, for homologous recombination. The integration in $\mathrm{EII}^{\mathrm{Bg} 1}$ (giving strains AG122 and AG119, respectively) deleted the C-terminal 194 of the predicted 635 amino acids, including the entire catalytic domain IIA and part of the membranespanning domain IIC. In the phospho- $\beta$-glucosidase knockouts (strains AG115 and AG117, respectively), the insertion truncated the last 110 of the 474 predicted amino acids, removing the $\mathrm{C}$-terminal glycosylhydrolase motif.

The pediocin sensitivity of the four insertional mutants was determined. All strains had the same phenotype as the respective original strain: L. monocytogenes AG122 

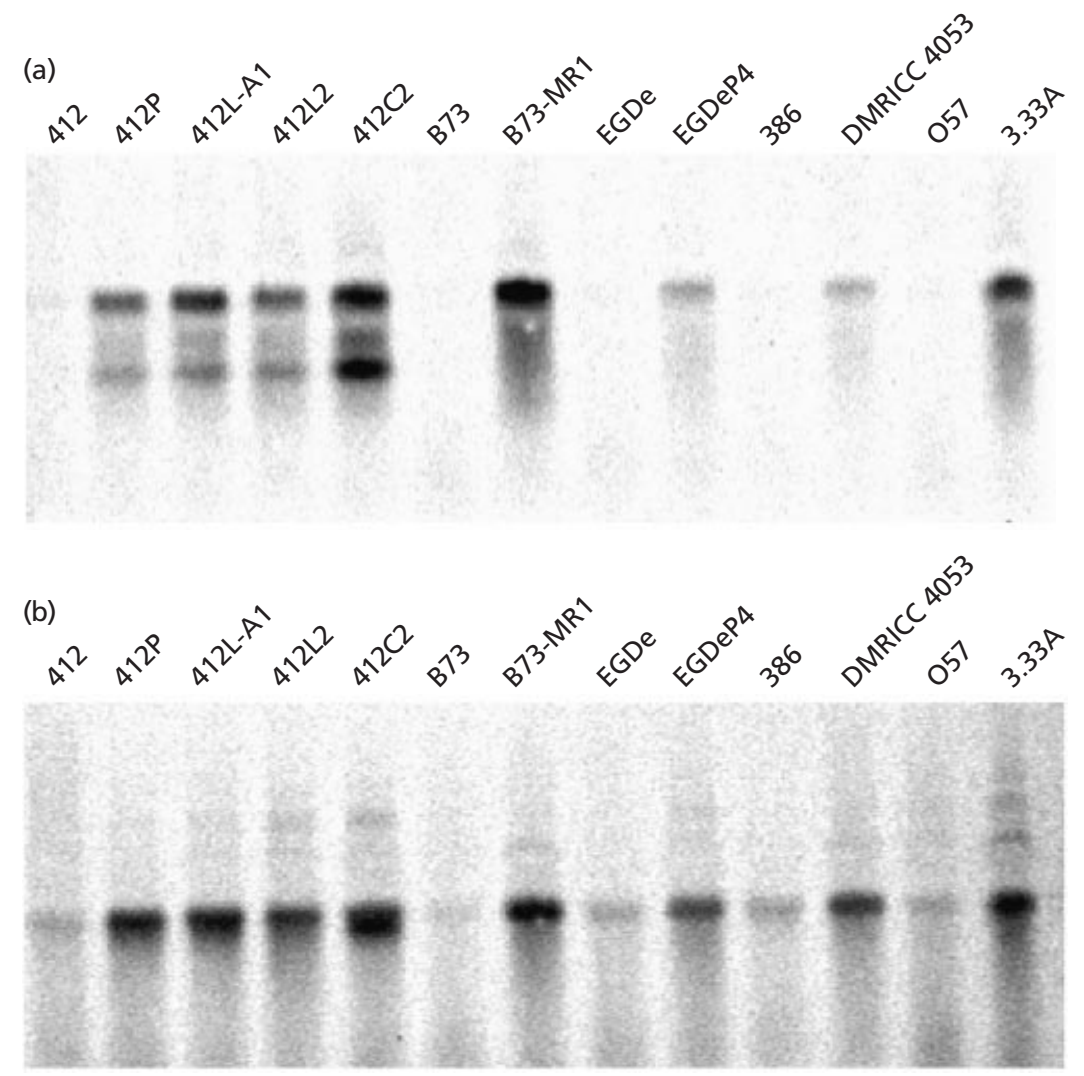

Fig. 1. Northern blot analysis of wild-type $L$. monocytogenes strains and derived spontaneous class Ila bacteriocin-resistant mutants, using internal gene fragments of the putative $\beta$-glucoside-specific PTS enzyme II, $\mathrm{EII}^{\mathrm{Bgl}}(\mathrm{a})$, and the phospho- $\beta$-glucosidase homologue (b) as probes. and AG115 were pediocin-sensitive, like L. monocytogenes 412, and L. monocytogenes AG117 and AG119 were pediocin-resistant, like L. monocytogenes 412P. In concordance, the MIC for leucocin A was unaffected by the insertion (Table 1).

\section{Analysis of protein expression by 2D gel electrophoresis}

Comparison of the protein profiles of the wild-type and spontaneous resistant mutants showed that one protein spot consistently disappeared following class IIa resistance development (Fig. 2). This change was observed for all five wild-type strains employed, and following exposure to each of the four tested class IIa bacteriocins. The protein spot also disappeared in resistant strains that had developed in a food system, either a saveloytype sausage or salmon juice. Additionally, this spot was not detected in the gels of the deletion and insertional mutants L. monocytogenes EGK51, EGK54 and EGY2 (Fig. 2).

Initial attempts at identifying the consistently missing spot by $\mathrm{N}$-terminal sequencing were inconclusive. To overcome this problem, zoom gels were made to improve the resolution of the region containing the spot. The results indicated that what appeared to be a single spot on normal gels appeared to consist of several spots on zoom gels. This cluster of spots was consistently present in L. monocytogenes EGDe, B73 and 412, and missing in L. monocytogenes EGY2, B73-MR1 and 412P, as shown for L. monocytogenes EGDe and EGY2 for example (Fig. 3). To further improve the resolution, the seconddimension running time was extended for the $L$. monocytogenes EGDe sample, and this clearly resolved the protein into a cluster of several spots (Fig. 3).

After tryptic in-gel digestion of the whole cluster from a zoom gel of L. monocytogenes EGDe and subsequent electrospray ionization, 19 putative peptide ions could be detected. Six ions were selected randomly for QTOF-based peptide micro-sequencing, which revealed the presence of two different proteins. One was the MptA subunit of a mannose-specific PTS enzyme II operon, mptACD (GenBank accession number AF397145, annotated as lmo0096; Dalet et al., 2001), which is identical to 17 of the $20 \mathrm{~N}$-terminal amino acids sequenced from a putative mannose-specific EII in $L$. monocytogenes B73 (Ramnath et al., 2000). The other was the 6-phospho-fructo-kinase (PFK; lmo1571). The relative amounts of MptA and PFK in the cluster were estimated to be $8: 1$. These two proteins have predicted molecular masses of 34.99 and $34.42 \mathrm{kDa}$, and $\mathrm{pI}$ values of 5.32 and $5 \cdot 46$, respectively; this compares with the observed molecular mass of $35 \mathrm{kDa}$ and the $\mathrm{pI}$ of $5 \cdot 35$ of the cluster. However, TOF-MS analysis of an adjacent 


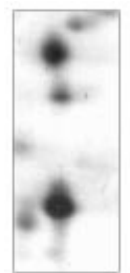

3.33A
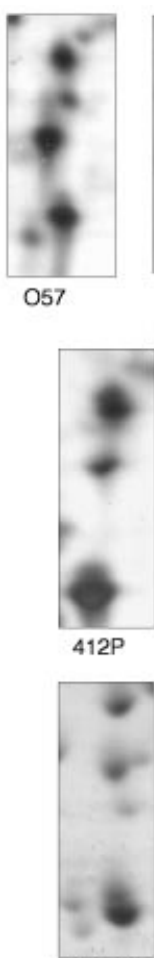

EGDeP4
DMRICC 4053
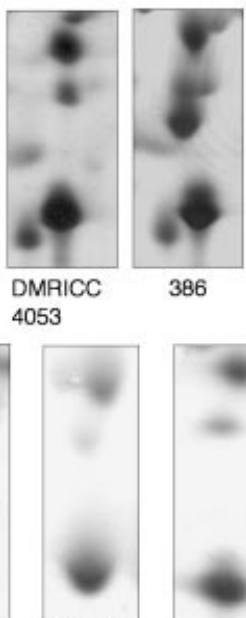

412L-A1

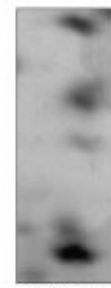

EGK51

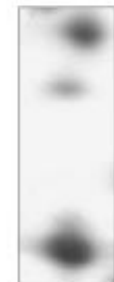

$412 \mathrm{C} 2$

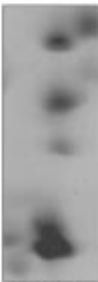

EGK54
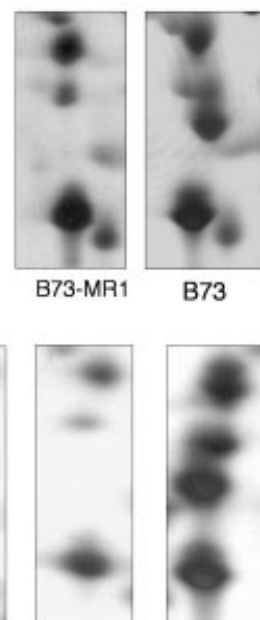

412

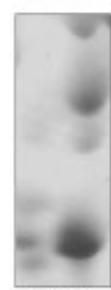

EGY2
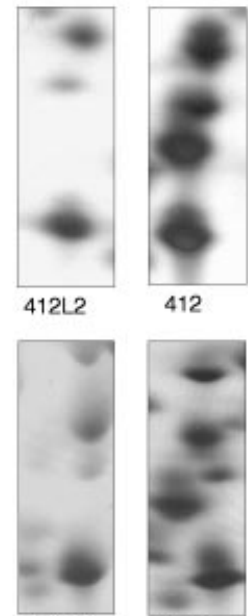

EGDe

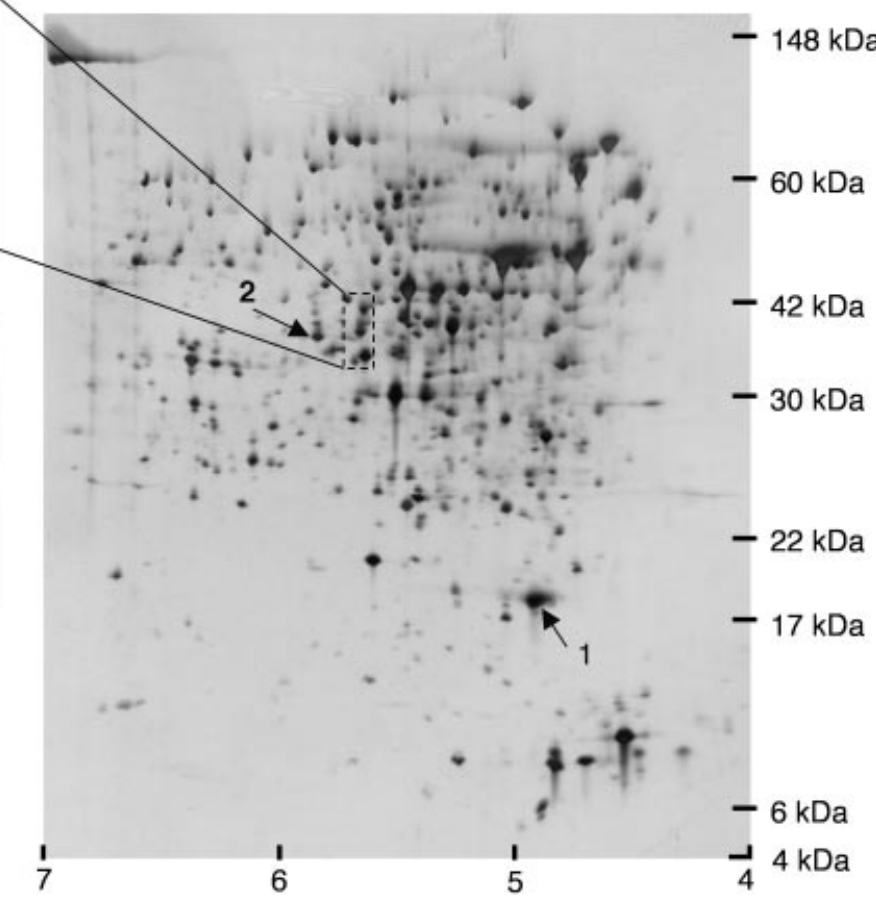

Fig. 2. 2D gel electrophoresis of wild-type $L$. monocytogenes strains and derived class lla bacteriocin-resistant mutants. The entire gel ( $\mathrm{pH}$ range 4-7) of $L$. monocytogenes B73 is shown; enlargements of the region encompassing the spot consistently missing following class lla bacteriocin resistance development are shown for the other strains. Arrows indicate the non-haem-iron-binding ferritin (1) and the 6-phosphofructokinase (2).
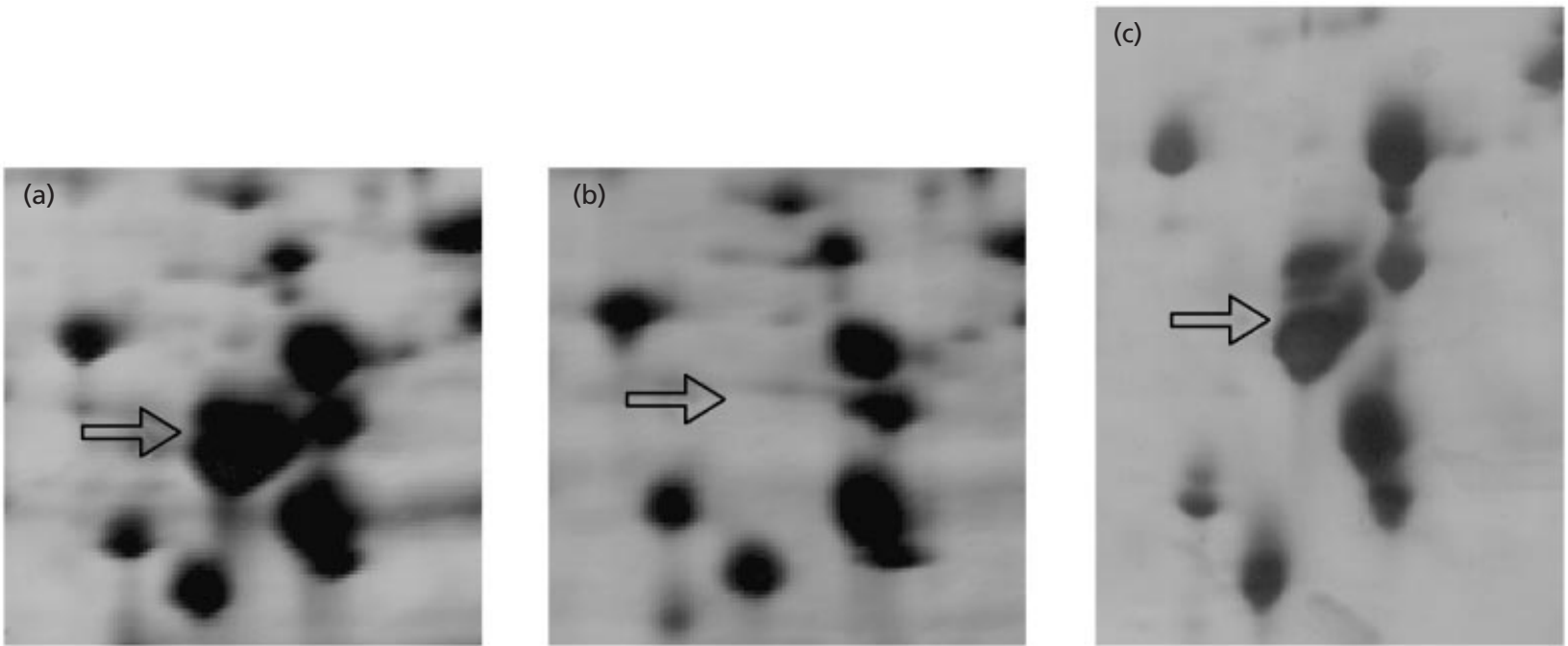

Fig. 3. Enlargements from 2D electrophoresis zoom gels ( $\mathrm{pH}$ range 5-6) of the region encompassing the spot (arrowed) consistently missing following class lla bacteriocin resistance development. Proteins were isolated from $L$. monocytogenes EGDe (a) and EGY2 (b). An extended-run zoom gel of L. monocytogenes EGDe (c) further resolved the spot into a cluster of several closely situated protein spots.

spot located to the lower left of the cluster (observed molecular mass $30 \mathrm{kDa}$, pI 5.79; Fig. 2), proved this also to contain PFK.
No other consistent changes were observed in the protein profiles of all the mutants tested. However, all four mutants of L. monocytogenes EGDe had an 
increased content of three high-molecular-mass protein spots (molecular mass range $78.5-84.8 \mathrm{kDa}$, pI range $4 \cdot 53-4 \cdot 66$ ), which presumably represents a strain-specific effect. In the other strains, no consistent strain-specific changes were found.

A non-haem-iron-binding ferritin was previously observed to be missing in an L. monocytogenes mutant with resistance to divercin V41 (Duffes et al., 2000). A protein with similar molecular mass and pI (Fig. 2) was found in all wild-type and mutant strains studied, showing no apparent change in expression. TOF-MS analysis of the corresponding spot from L. monocytogenes EGDe confirmed its identity as the non-haemiron-binding ferritin.

\section{DISCUSSION}

\section{The expression changes of different PTS systems are part of the same general resistance mechanism}

In previous work, two different changes in PTS expression were correlated to spontaneous development of resistance to class IIa bacteriocins in L. monocytogenes (Gravesen et al., 2000; Ramnath et al., 2000). The results presented in this paper show that both changes were evident in all eight independently isolated spontaneous L. monocytogenes mutants with high-level resistance to class IIa bacteriocins. All strains showed an increased expression of two putative $\beta$-glucoside-specific PTS genes, EII ${ }^{\mathrm{Bg} 1}$ and a phospho- $\beta$-glucosidase homologue, and all strains no longer synthesized the MptA subunit from a mannose-specific PTS, EII $\mathrm{t}$. Ad . Aditionally, the increased $\beta$-glucoside-specific PTS expression was seen in numerous other spontaneous mutants (this work and Gravesen et al., 2000). These results strongly indicate that spontaneous class IIa resistance in L. monocytogenes is developed by one general mechanism that confers the two diverging PTS expression changes, and that this mechanism would also be expected to prevail in strains from food products.

Expression of $m p t A C D$ is controlled by the $\sigma^{54}$ transcription factor and the activator ManR (Dalet et al., 2001). Knockout mutants of ManR or MptA, which were resistant to mesentericin Y105 (Dalet et al., 2001) and to all class IIa bacteriocins used in this study, also had increased expression of $\mathrm{EII}^{\mathrm{Bg}}$. This observation corroborates the hypotheses that the mannose and $\beta$ glucoside-specific PTS expression changes are part of the same resistance mechanism, and also indicates that the class IIa resistance mechanism conferring spontaneous, high-level resistance in L. monocytogenes is related to the mannose PTS-mediated effects described by defined mutations (Dalet et al., 2001).

A divericin 41-resistant mutant of L. monocytogenes $\mathrm{P}$ lacked at least nine protein spots (Duffes et al., 2000), two of which had a molecular mass and $\mathrm{pI}$ very similar to the MptA cluster. It is therefore possible that this mutant also acquired resistance by the same general mechanism; however, verification of this hypothesis would require identification of the proteins in these two spots.

An important aspect of resistance is whether the same mechanism is acquired in different species or genera. Listeria innocua is a non-pathogenic species with high genomic similarity to L. monocytogenes (Glaser et al., 2001). Northern analysis with L. monocytogenes probes showed that a class IIa bacteriocin-resistant mutant of each of five L. innocua wild-type strains similarly had increased expression of $\mathrm{EII}^{\mathrm{Bgl}}$ and the phospho- $\beta$ glucosidase (results not shown). In Enterococcus faecalis, expression of a mannose PTS enzyme II is also involved in class IIa bacteriocin sensitivity (Héchard et al., 2001). Altogether, the results strongly suggest that class IIa bacteriocin resistance is conferred by the same general mechanism in L. monocytogenes, L. innocua and E. faecalis, and conceivably also in some other Gram-positive organisms.

\section{Direct and indirect effects - how is class Ila bacteriocin resistance acquired?}

It was recently reported that the enantiomer of leucocin A was not biologically active (Yan et al., 2000), which strongly indicates that activity of class IIa bacteriocins requires chiral interaction with a docking molecule. It is tempting to speculate that the general resistance mechanism involves elimination of this docking molecule.

EII ${ }^{\text {Bgl }}$ and the putative phospho- $\beta$-glucosidase were suggested to be encoded in the same operon, based on homology (Gravesen et al., 2000). However, according to the recently released L. monocytogenes EGDe genome sequence (Glaser et al., 2001), they are located at separate positions on the chromosome. Interruption of $\mathrm{EII}^{\mathrm{Bg} 1}$ or the phospho- $\beta$-glucosidase in the resistant mutant L. monocytogenes $412 \mathrm{P}$ did not affect IIa resistance. Therefore, the increased expression of either of these genes does not per se cause class IIa bacteriocin resistance, but is presumably a natural regulatory consequence of acquired resistance. Prevention of $m p t A C D$ expression directly conferred resistance (Dalet et al., 2001), suggesting that the membrane component, the MptC-MptD complex, could function as target for class IIa bacteriocins. Expression of $m p t$ could be prevented through mutation in rpoN, manR or $m p t$. The multiple possibilities could explain the observation of relatively high IIa resistance frequencies of approximately $10^{-6}$ (Gravesen et al., 2002). The specific location of the mutation in a resistant strain will determine the extent of the changes in the strain, i.e. a mutation in $\sigma^{54}$ would have more extensive consequences than a mutation in mpt. Abolished $m p t A C D$ expression could cause up-regulation of $\mathrm{EII}^{\mathrm{Bg} 1}$ and the phospho- $\beta$-glucosidase expression; this is similar to the observation that a mannose PTS regulates expression of other PTS, including $\beta$-glucoside-specific enzymes, as part of the carbon catabolite repression in Streptococcus salivarius and Lactobacillus pentosus (Bourassa \& Vadeboncoeur, 1992; Chaillou et al., 2001; Gauthier et al., 1990). 
Supporting this hypothesis, a sequence with only two mismatches to the cre (catabolite-responsive element; Stülke \& Hillen, 1999) consensus overlaps a putative $-35 /-10$ promoter upstream of the EII ${ }^{\mathrm{Bg} 1}$ reading frame.

An additional 28 aa domain present in the MptD subunit of EII $\mathrm{t}_{\mathrm{Man}}$ compared to other mannose PTS EII sequences was indicated to possibly be involved in IIa sensitivity, since L. monocytogenes EGY2, which has an in-frame deletion of the additional domain, was resistant to mesentericin Y105 (Dalet et al., 2001). However, the 2D gel analysis showed that L. monocytogenes EGY2 did not produce detectable amounts of MptA, indicating that the mptACD operon is repressed. The repression could be due to the deletion rendering the permease functionally inactive, which in turn could modify the expression through a regulatory cascade.

The two other candidate proteins potentially involved in class IIa bacteriocin resistance, PFK and the non-haem iron-binding ferritin, are apparently not the causative factor. The presence of PFK in two different protein spots could be due to post-translational modifications of the protein, where phosphorylation and/or truncation could result in the lower molecular mass and higher $\mathrm{pI}$ observed in the spot adjacent to the consistently disappearing cluster. However, the adjacent PFK spot had similar intensity in wild-type strains and their derived mutants, indicating that there is no overall change in PFK expression related to class IIa bacteriocin resistance. The non-haem iron-binding ferritin, which was missing in one mutant (Duffes et al., 2000), did not have any difference in expression in the eight mutants in this study. This observation and the strain-specific changes seen in the L. monocytogenes EGDe mutants underline the importance of analysing several wild-type and mutant strains.

All in all, we suggest that the presently available knowledge allows the following conclusions. Resistance to IIa bacteriocins is acquired through one general mechanism in L. monocytogenes and at least some other Gram-positive organisms. This mechanism is characterized by prevention of $\mathrm{EII}_{\mathrm{t}}^{\text {Man }}$ synthesis and upregulation of $\mathrm{EII}^{\mathrm{Bgl}}$ and the phospho- $\beta$-glucosidase. Upregulated $\mathrm{EII}^{\mathrm{Bgl}}$ and phospho- $\beta$-glucosidase expression is not a direct cause of resistance, but is presumably a regulatory consequence of abolished mptACD expression. Prevention of $m p t$ expression directly confers resistance. Although present evidence suggests that the $\mathrm{MptC}-\mathrm{MptD}$ complex interacts as target with class IIa bacteriocins, more work is required to elucidate how shutdown of $m p t$ expression actually causes resistance.

\section{ACKNOWLEDGEMENTS}

We thank S. Aimoto and K. Tamura for the generous gift of synthetic leucocin A. We also thank Anette Granly Koch for supplying listerial strains, and Lilian Nilsson for strains and bacteriocin fermentate. The expert technical assistance of Hanne Mordhorst and Lene Gertman is greatly appreciated. This work was supported by the Food Biotechnology Pro- gramme of the Danish Ministry for Food, Agriculture, and Fisheries (BIOT99-8), and by a grant from The Danish Rectors' Conference and the National Research Foundation (South Africa) to M.R. and J. W.H.

\section{REFERENCES}

Ben Ambarek, P. K. \& Huss, H. H. (1993). Heat resistance of Listeria monocytogenes in vacuum packaged pasteurized fish fillets. Int J Food Microbiol 20, 85-95.

Bourassa, S. \& Vadeboncoeur, C. (1992). Expression of an inducible enzyme II fructose and activation of a cryptic enzyme II glucose in glucose-grown cells of spontaneous mutants of Streptococcus salivarius lacking the low-molecular-mass form of III ${ }^{\text {man }}$, a component of the phosphoenolpyruvate:mannose phosphotransferase system. J Gen Microbiol 138, 769-777.

Chaillou, S., Postma, P. W. \& Pouwels, P. H. (2001). Contribution of the phosphoenolpyruvate:mannose phosphotransferase system to carbon catabolite repression in Lactobacillus pentosus. Microbiology 147, 671-679.

Chakraborty, T., Leimeister-Wachter, M., Domann, E., Hartl, M., Goebel, W., Nichterlein, T. \& Notermans, S. (1992). Coordinate regulation of virulence genes in Listeria monocytogenes requires the product of the prfA gene. J Bacteriol 174, 568-574.

Cleveland, J., Montville, T. J., Nes, I. F. \& Chikindas, M. L. (2001). Bacteriocins: safe, natural antimicrobials for food preservation. Int J Food Microbiol 71, 1-20.

Dalet, K., Cenatiempo, Y., Cossart, P. \& Héchard, Y. (2001). A $\sigma^{54}$ dependent PTS permease of the mannose family is responsible for sensitivity of Listeria monocytogenes to mesentericin Y105. Microbiology 147, 3263-3269.

Duffes, F., Jenoe, P. \& Boyaval, P. (2000). Use of two-dimensional electrophoresis to study differential protein expression in divercin V41-resistant and wild-type strains of Listeria monocytogenes. Appl Environ Microbiol 66, 4318-4324.

Dykes, G. A. \& Hastings, J. W. (1998). Fitness costs associated with class IIa bacteriocin resistance in Listeria monocytogenes B73. Lett Appl Microbiol 26, 5-8.

Ennahar, S., Sashihara, T., Sonomoto, K. \& Ishizaki, A. (2000). Class IIa bacteriocins: biosynthesis, structure and activity. FEMS Microbiol Rev 24, 85-106.

Gauthier, L., Bourassa, S., Brochu, D. \& Vadeboncoeur, C. (1990). Control of sugar utilization in oral streptococci. Properties of phenotypically distinct 2-deoxyglucose-resistant mutants of Streptococcus salivarius. Oral Microbiol Immunol 5, 352-359.

Glaser, P., Frangeul, L., Buchrieser, C. \& 52 other authors (2001). Comparative genomics of Listeria species. Science 294, 849-852.

Gravesen, A., Warthoe, P., Knøchel, S. \& Thirstrup, K. (2000). Restriction fragment differential display of pediocin-resistant Listeria monocytogenes 412 mutants shows consistent overexpression of a putative $\beta$-glucoside-specific PTS system. Microbiology 146, 1381-1389.

Gravesen, A., Jydegaard Axelsen, A.-M., Mendes da Silva, J., Hansen, T. B. \& Knøchel, S. (2002). Frequency of bacteriocin resistance development and associated fitness costs in Listeria monocytogenes. Appl Environ Microbiol 68, 756-764.

Héchard, Y., Pelletier, C., Cenatiempo, Y. \& Frere, J. (2001). Analysis of $\sigma^{54}$-dependent genes in Enterococcus faecalis: a mannose PTS permease (EII ${ }^{\text {Man }}$ ) is involved in sensitivity to a bacteriocin, mesentericin Y105. Microbiology 147, 1575-1580.

Nilsson, L., Gram, L. \& Huss, H. H. (1999). Growth control of Listeria monocytogenes on cold-smoked salmon using a competitive lactic acid bacteria flora. J Food Protection 62, 336-342. 
Papathanasopoulos, M. A., Krier, F., Revol-Junelles, A. M. Lefebvre, G., Le Caer, J. P., von Holy, A. \& Hastings, J. W. (1997). Multiple bacteriocin production by Leuconostoc mesenteroides TA33a and other Leuconostoc/Weissella strains. Curr Microbiol 35, 331-335.

Park, S. F. \& Stewart, G. S. (1990). High-efficiency transformation of Listeria monocytogenes by electroporation of penicillin-treated cells. Gene 94, 129-132.

Postma, P. W., Lengeler, J. W. \& Jacobson, G. R. (1993). Phosphoenolpyruvate:carbohydrate phosphotransferase systems of bacteria. Microbiol Rev 57, 543-594.

Ramnath, M., Beukes, M., Tamura, K. \& Hastings, J. W. (2000). Absence of a putative mannose-specific phosphotransferase system enzyme IIAB component in a leucocin A-resistant strain of Listeria monocytogenes, as shown by two-dimensional sodium dodecyl sulfate-polyacrylamide gel electrophoresis. Appl Environ Microbiol 66, 3098-3101.

Rasch, M. \& Knøchel, S. (1998). Variations in tolerance of Listeria monocytogenes to nisin, pediocin PA-1 and bavaricin A. Lett Appl Microbiol 27, 275-278.
Rechinger, K. B., Siegumfeldt, H., Svendsen, I. \& Jakobsen, M. (2000). 'Early' protein synthesis of Lactobacillus delbrueckii ssp. bulgaricus in milk revealed by $\left[{ }^{35} \mathrm{~S}\right]$ methionine labeling and twodimensional gel electrophoresis. Electrophoresis 21, 2660-2669.

Robichon, D., Gouin, E., Debarbouille, M., Cossart, P., Cenatiempo, Y. \& Héchard, Y. (1997). The $r p o N\left(\sigma^{54}\right)$ gene from Listeria monocytogenes is involved in resistance to mesentericin Y105, an antibacterial peptide from Leuconostoc mesenteroides. J Bacteriol 179, 7591-7594.

Stülke, J. \& Hillen, W. (1999). Carbon catabolite repression in bacteria. Curr Opin Microbiol 2, 195-201.

Yan, L. Z., Gibbs, A. C., Stiles, M. E., Wishart, D. S. \& Vederas, J. C. (2000). Analogues of bacteriocins: antimicrobial specificity and interactions of leucocin A with its enantiomer, carnobacteriocin B2, and truncated derivatives. J Med Chem 43, 4579-4581.

Received 13 February 2002; revised 10 April 2002; accepted 17 April 2002. 